\title{
BEHAVIOR OF ULTRA-HIGH STRENGTH CONCRETE BEAMS
}

Abdel Moneim Tawfic ${ }^{1}$, Mohamed Taha Nooman ${ }^{2}$, Adel Amer ${ }^{3}$

${ }^{1}$ Higher Technological Institute $10^{\text {th }}$ Ramadan City

${ }^{2,3}$ Civil Eng.Dept.,Faculty of Engineering ,Al Azhar University

Received :24 Augst. 2021 Accepted:23 Sept. 2021

\begin{abstract}
In the present investigation, the behavior of ultra-high strength concrete (UHSC) beams containing different reinforcement ratio and stirrups was investigated. The concrete was successfully prepared from Egyptian local materials. Series of cubes and cylinders were prepared to examine the compressive and splitting strengths of the UHSC at different ages. Eight reinforced beams have been prepared and tested at 28 days. The outcomes indicated that the compressive strength ratio between cylinders and cubes samples are $90 \%, 87 \%$ and $85 \%$ at 7,28, and 56 days respectively, while the ratio between tensile strength to compressive strength is $38.5 \%$ and $36.6 \%$ at 7 and 28 days respectively. Furthermore, the beams test outcomes were presented and discussed as deflection, ultimate loads, cracking, failure modes and ductility.
\end{abstract}

KEYWORDS: Ultra-high strength concrete (UHSC), Deflection, Cracks, Ultimate loads, Ductility

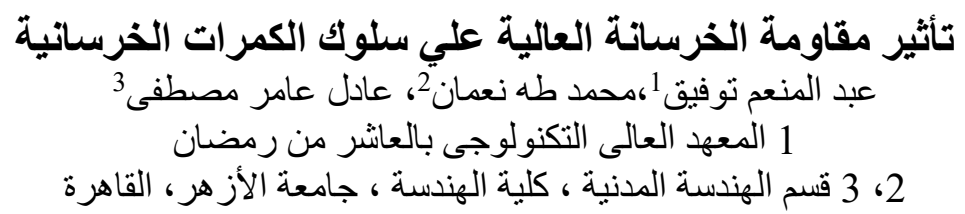

الملخص العربي

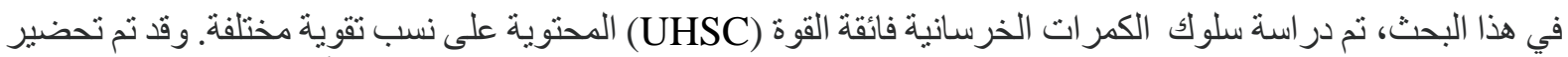

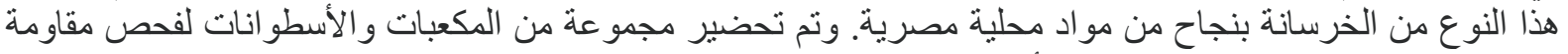

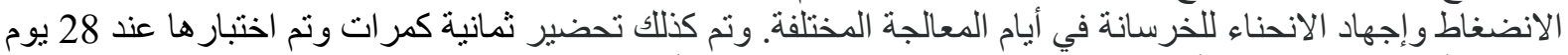

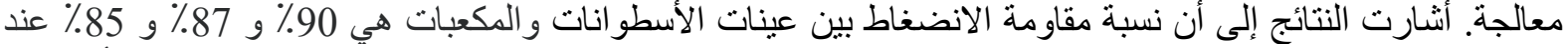

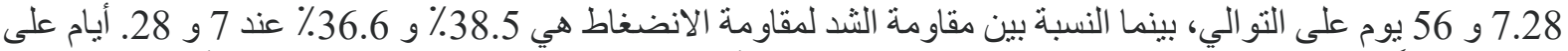

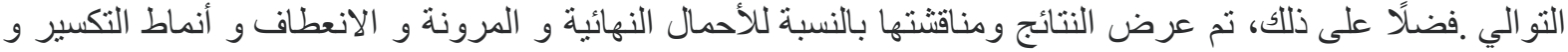

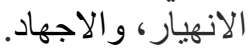

الكلمات المفتاحية: خرسانة فائقة القوة (UHSC) ، انعطاف ، شقوق ، أحمال قصوى ، مرونة. 


\section{INTRODUCTION}

Concrete is the most important material for engineering structures and widely used in buildings, bridges, roads, and different applications [1]. During the past few years, high strength concrete (HSC) has gradually become a hot topic and generated increasing interest amongst civil and structural engineers. Recently, the commercial usage of HSC increases progressively due to outstanding engineering properties that offers and the life cycle costperformance ratio [2-5]. HSC possesses prodigious benefits, including high compressive strength and elastic modulus, and vast economic benefits brought by reducing the dimension of structure sections comparing with the ordinary concrete [6]. Therefore, a large number of HSC is utilized for tall buildings and long-span structures. Ultra-high strength concrete (UHSC) is another kind of HSC that has been regarded as a promising material to change the concrete industry. This concrete consists of portland cement, fine sand or quartz, silica fume, water reducing admixture and steel fibers [5]. UHSC could be economically prepared by concrete plants all over the world owing to availabilities of additives and admixture such as silica fume and water reducing admixture [6,7]. The development of UHSC is one of the safety features in nuclear reactors. UHSC can be used in nuclear plants to minimize the radiation dose of radioactive sources and protect the nuclear installations from failure or used as storage facilities for nuclear waste [8].

UHSC containing different types and contents of coarse aggregate gives certain advantages over the conventional aggregates. Xiong et al. [9] investigated the coarse aggregates effect on the mechanical and physical properties of UHSC. Based on the experimental test results, it was found that the workability and compressive strength have been enhanced by mixing the larger-size coarse aggregates. Rozalija and Darwin [10] reported that HSC containing basalt aggregate gives higher mechanical properties than HSC containing limestone. The behavior is attributed to the intrinsic properties of the rock. Recently, the main challenge that faces UHSC is to produce UHSC from low-cost local materials and apply it in the design of different concrete structures. Therefore, Huang et al. [11] examined the influence of slag as a low cost recycled material on the properties of UHSC. The outcomes illustrated that a remarkable enhancement in flowability and mechanical properties of UHSC can be achieved when slag is used.

On the other hand, numerous previous investigations [12-15] have been achieved to evaluate the performances of structural elements prepared from UHSC. Kimura et al. [16] evaluated the behavior of UHSC columns under seismic conditions. The outcomes indicated that steel fibers improved the various structural properties. Kamal et al. [17] assessed the behavior of UHSC beams containing different types of fibers. In this study, beams with and without shear reinforcements have been evaluated in flexure. The examinations gave superior considerations to the deflection behavior under different loadings. The experimental results illustrated that increment of cracks at the final loading is owing to fibers which results in reducing the width of cracks. The behavior produced increasing stiffness and higher maximum loads values.

Unfortunately, most of concrete structures design codes around the world limit the use of UHSC unless there are physical tests conducted to determine its behavior. Therefore, the 
present work was devoted to preparing ultra-high strength concrete from local Egyptian materials and investigate the behavior of reinforced beams.

\section{EXPERIMENTAL WORK}

\subsection{Materials}

\subsubsection{Cement}

The cement utilized in all different test specimens was CEM I 52.5N. It was produced by Siena Cement Company. The properties of this type of cement are given in Table 1.

Table 1. Physical Properties for CEM I 52.5N

\begin{tabular}{|l|c|c|}
\hline \multicolumn{1}{|c|}{ Properties } & $\begin{array}{c}\text { Test } \\
\text { Result }\end{array}$ & Limits* $^{*}$ \\
\hline $\begin{array}{l}\text { Percentage of water for standard consistency } \\
(\%)\end{array}$ & 25.24 & - \\
\hline Specific surface area (Blain) $\left(\mathrm{m}^{2} / \mathrm{kg}\right)$ & 345 & - \\
\hline Soundness (Le-Chatelier) $(\mathrm{mm})$ & 1.0 & Less than $10 \mathrm{~mm}$ \\
\hline $\begin{array}{l}\text { Compressive strength of standard mortar at } \\
2 \text { days (MPa) }\end{array}$ & 21.5 & More than $10 \mathrm{MPa}$ \\
\hline $\begin{array}{l}\text { Compressive strength of standard mortar at } \\
28 \text { days (MPa) }\end{array}$ & 51.5 & $\begin{array}{l}42.5<\mathrm{X}<62.5 \\
\mathrm{MPa}\end{array}$ \\
\hline
\end{tabular}

*All limits are according to Egyptian Standard Specifications 47561/2013

\subsubsection{Silica Fumes}

A commercial silica fumes was used in this investigation. It was locally purchased from Sika Chemicals Company, and its physical properties are presented in Table 2.

Table 2. Physical Properties for Silica fumes

\begin{tabular}{|c|c|}
\hline Property & Test Results* \\
\hline Specific Surface Area $\left(\mathbf{m}^{2} / \mathbf{k g}\right)$ & $10^{3} \times 17.8$ \\
\hline Particle Size $(\boldsymbol{\mu m})$ & 7.00 \\
\hline Bulk Density $\left(\mathbf{k g} / \mathbf{m}^{3}\right)$ & 345 \\
\hline Specific Gravity & 2.15 \\
\hline Color & Light Gray \\
\hline
\end{tabular}

*By the manufacturer data sheet.

\subsubsection{Aggregates}

In the present study, an Egyptian crushed basalt with physical properties depicted in Table 3 was utilized as a coarse aggregate. The basalt possesses a maximum nominal size of 
$10 \mathrm{~mm}$. Its size distribution is shown in Table 4. It falls within the limits of aggregate gradation according to the ASTM standard C33-82 and Egyptian code. The fine aggregate was a natural sand with a nominal size of $\sim 2.0 \mathrm{~mm}$. Also, its physical properties is given in Table 3 . The ratio between the coarse and fine aggregate used in this study was $2: 1$, this ratio was used because of the high fines content of ultra-high strength concrete.

Table 3. Basic properties of aggregates

\begin{tabular}{|c|c|c|}
\hline Property & Coarse aggregate & Fine aggregate \\
\hline Specific gravity (SSD) & 2.70 & 2.50 \\
\hline Unit weight $\left(\mathrm{t} / \mathrm{m}^{3}\right.$ ) & 1.67 & 1.62 \\
\hline Absorption (\%) & 1.53 & - \\
\hline Clay and other fine materials (\%) & 0.12 & 1.4 \\
\hline Impact index (\%) & 14.6 & - \\
\hline Flakiness index (\%) & 14.3 & - \\
\hline Elongation index (\%) & 16.6 & - \\
\hline Abrasion resistance (\%) & 18.4 & - \\
\hline
\end{tabular}

Table 4. Sieve Analysis for basalt

\begin{tabular}{|c|c|r|r|r|r|r|r|r|c|}
\hline \multicolumn{2}{|c|}{ Sieve Size(mm) } & $\mathbf{5 0}$ & $\mathbf{3 7 . 5}$ & $\mathbf{2 0}$ & $\mathbf{1 4}$ & $\mathbf{1 0}$ & $\mathbf{5}$ & $\mathbf{2 . 3 6}$ & $\mathbf{1 . 1 8}$ \\
\hline $\begin{array}{c}\text { Passing } \\
(\%)\end{array}$ & $D_{10}$ & 100 & 100 & 100 & 100 & 97.53 & 10.88 & 0.42 & 0.03 \\
\cline { 2 - 9 } & $D_{5}$ & 100 & 100 & 100 & 100 & 99.95 & 95.26 & 0.76 & 0.28 \\
\hline
\end{tabular}

\subsubsection{Water}

A fresh clean tap water was used for preparing and curing all different samples. The water/cement ratio utilized in this study was 0.23 .

\subsubsection{Steel}

High grade steel bars with diameters of 12 and $16 \mathrm{~mm}$ were used.

\subsubsection{Superplasticizier}

Sikament ${ }^{\circledR}-163$ (complies with A.S.T.M. C 494-92 Type A and F) was utilized as a super plasticizer (sp). It was purchased from Sika Chemicals Company.

\subsection{Mixing procedure}

A vertical single-spindle mixer has been utilized in the concrete mixing process. Firstly, The SP and water were initially mixed in a plastic container for $2 \mathrm{~min}$. Then the components of the concrete (cement, silica fumes, coarse and fine aggregates) were put gradually inside the blender and mixed for $5 \mathrm{~min}$ in the dry conditions to increase the homogeneity between the different components. Finally, the water and SP were gradually added in the mixer. The mixing process continued for about $3 \mathrm{~min}$. Table 5 gives the mix proportion of concrete samples. 
Table 5. Mix proportion of concrete samples.

\begin{tabular}{|c|c|c|c|c|c|c|}
\hline $\begin{array}{c}\text { Cement } \\
\left(\mathbf{K g} / \mathbf{m}^{\mathbf{3}}\right)\end{array}$ & $\begin{array}{c}\text { Silica } \\
\text { fumes } \\
\left(\mathbf{K g} / \mathbf{m}^{\mathbf{3}}\right)\end{array}$ & $\begin{array}{c}\text { Coarse } \\
\text { aggregate } \\
\left(\mathbf{K g} / \mathbf{m}^{\mathbf{3}}\right)\end{array}$ & $\begin{array}{c}\text { Sand } \\
\left(\mathbf{K g} / \mathbf{m}^{\mathbf{3}}\right)\end{array}$ & $\begin{array}{c}\text { Water } \\
\left(\mathbf{K g} / \mathbf{m}^{\mathbf{3}}\right)\end{array}$ & $\begin{array}{c}\mathbf{S P} \\
\left(\mathbf{K g} / \mathbf{m}^{3}\right)\end{array}$ & W/c \\
\hline 600 & 60 & 951 & 687.40 & 158.4 & 12 & 0.24 \\
\hline
\end{tabular}

The concrete mixes were casted in the laboratory of Al-Azhar University. The slump test was conducted immediately after mixing. In order to obtain a relation between the cubic concrete compressive strength and cylindrical concrete compressive strength as well as the compressive strength for all specimens at test day, 32 cubes and cylinders from each concrete mix were casted and tested at different ages to be able to compare with different international design codes. It worth noting that the ECP 203-2007 and BS 8110-97 uses the concrete cubic strength while some other international codes such as ACI 318-14 and CSA A23.3-04 use the cylinder compressive strength. For each concrete mix, $10 \mathrm{~cm}$ size cubes have been casted to determine the compressive strength. While cylinders $(\varnothing=15 \mathrm{~cm}$ diameter and length $=30 \mathrm{~cm})$ were used in the tests of splitting tensile. All specimens have been casted in steel moulds and hand compacted. After 24 hours of the casting process, all specimens have been demoluded and transferred to curing regimes. The curing technique was the standard moist curing that the specimens were immersed in fresh water at ambient temperature until the time of testing.

\subsection{MECHANICAL PROPERTIES OF CONCRETE MIX}

\subsection{Compressive strength}

Compressive strengths of UHSC was evaluated at different curing time (7, 28 and 56 days) using a universal machine of $200 \mathrm{kN}$ capacity. The load was slowly applied on standard cubes $(100 \times 100 \times 100 \mathrm{~mm}$.) and cylinders with $(\varnothing=100 \mathrm{~mm}$ and length $=200 \mathrm{~mm})$. The concrete specimens were removed from water bath and dried using a cloth before testing.

\subsubsection{Splitting tensile strength}

The splitting tensile strength of UHSC was also performed according to ASTM C4692994 standard test method using cylinders with $(\varnothing=150 \mathrm{~mm}$ and length $=300 \mathrm{~mm})$.

\subsection{Beams preparations and testing procedures}

So as to achieve our experimental program, moulds fabricated from wood have been utilized in the casting of the reinforced ultra-high strength concrete beams. The moulds were firmed enough to inhibit any movement through incorporating the UHSC into the moulds. A strain gauges having $120 \mathrm{X}$ resistance have been carefully fixed to determine the strain in the middle of the two longitudinal before casting the beams. The strain gauges were installed on the carbon steel bars by special types of glues. After preparing the concrete mix, the beams were directly casted in the moulds and then they were compacted using a vibrating machine. The specimens were casted on $t$ a horizontal position. Then the beams were stored in the laboratory. After that they were de-moulded after $24 \mathrm{~h}$ and cured in water at ambient temperature for 28 days.

Seven UHSC beams were prepared with and without web reinforcement in the present research. The beams have been prepared to have satisfactory resistance for flexure behavior. Beams with dimensions of $100 \times 120 \times 1600 \mathrm{~mm}$ were casted and examined up to failure. 
The beams under consideration were either reinforced with two bottom rebars with $(\varnothing=10$ $\mathrm{mm}$ and reinforcement ratio $(\mathrm{q})=1.2 \%)$ or $(\varnothing=12 \mathrm{~mm}$ and reinforcement ratio $(\mathrm{q})=1.2 \%)$. More details on the reinforcements of the beams can be presented in Table 6 and Fig 1.

Table 6. Test results of tested beams.

\begin{tabular}{|c|c|c|c|c|c|c|c|c|c|}
\hline \multirow{2}{*}{$\begin{array}{l}\text { No. of } \\
\text { stirrups }\end{array}$} & \multirow[b]{2}{*}{$\begin{array}{c}\text { Reinforcement } \\
\text { Details }\end{array}$} & \multirow[b]{2}{*}{$\begin{array}{l}\text { No of } \\
\text { stirpes }\end{array}$} & \multirow{2}{*}{$\begin{array}{l}\text { Comp. } \\
\text { strength } \\
\mathrm{kg} / \mathrm{cm}^{2}\end{array}$} & \multicolumn{2}{|c|}{$\begin{array}{c}\text { Cracking load } \\
\text { (t) }\end{array}$} & \multirow{2}{*}{$\begin{array}{c}\begin{array}{c}\text { Deflection } \\
(\mathrm{mm})\end{array} \\
\text { (D) } \\
\max \end{array}$} & \multicolumn{2}{|c|}{$\begin{array}{l}\text { Mode } \\
\text { of failure }\end{array}$} & \multirow{2}{*}{$\begin{array}{c}\begin{array}{c}\text { Frist } \\
\text { visible } \\
\text { crake }\end{array} \\
\begin{array}{c}\text { Failure } \\
\text { load\% }\end{array}\end{array}$} \\
\hline & & & & $\begin{array}{l}\text { (P) first } \\
\text { visible } \\
\text { crake }\end{array}$ & $\begin{array}{c}(\mathrm{P}) \\
\text { failure }\end{array}$ & & D.T & D.S & \\
\hline BB1 & $\begin{array}{c}2 \varnothing 8 \\
2 \varnothing 12\end{array}$ & $8 \varnothing 6$ & 1007 & 3,01 & 8.01 & 43.13 & $\sqrt{ }$ & & $37.5 \%$ \\
\hline BB2 & $\begin{array}{l}2 \varnothing 8 \\
2 \varnothing 10\end{array}$ & $8 \varnothing 6$ & 1007 & 4.00 & 10.50 & 41.59 & $\sqrt{ }$ & & $38.095 \%$ \\
\hline BB3 & $\begin{array}{l}2 \varnothing 8 \\
2 \varnothing 16 \\
\end{array}$ & $8 \varnothing 6$ & 1007 & 4.01 & 11.70 & 36.44 & $\sqrt{ }$ & & $34.188 \%$ \\
\hline GB1 & $\begin{array}{l}2 \varnothing 8 \\
2 \varnothing 16\end{array}$ & $5 \varnothing 6$ & 1007 & 4.9 & 10.01 & 17.25 & & $\sqrt{ }$ & $0.49 \%$ \\
\hline GB2 & $\begin{array}{l}2 \varnothing 8 \\
2 \varnothing 16 \\
\end{array}$ & $5 \varnothing 8$ & 1007 & 9.01 & 9.50 & 21.95 & & $\sqrt{ }$ & $94.73 \%$ \\
\hline GB3 & $\begin{array}{l}2 \varnothing 8 \\
2 \varnothing 16 \\
\end{array}$ & $3 \varnothing 6$ & 1007 & 5.7 & 5.70 & 11.38 & & $\sqrt{ }$ & $100 \%$ \\
\hline GB4 & $\begin{array}{l}2 \varnothing 8 \\
2 \varnothing 16\end{array}$ & $10 \varnothing 6$ & 1007 & 4.5 & 16.01 & 33.62 & & V & $28.12 \%$ \\
\hline
\end{tabular}




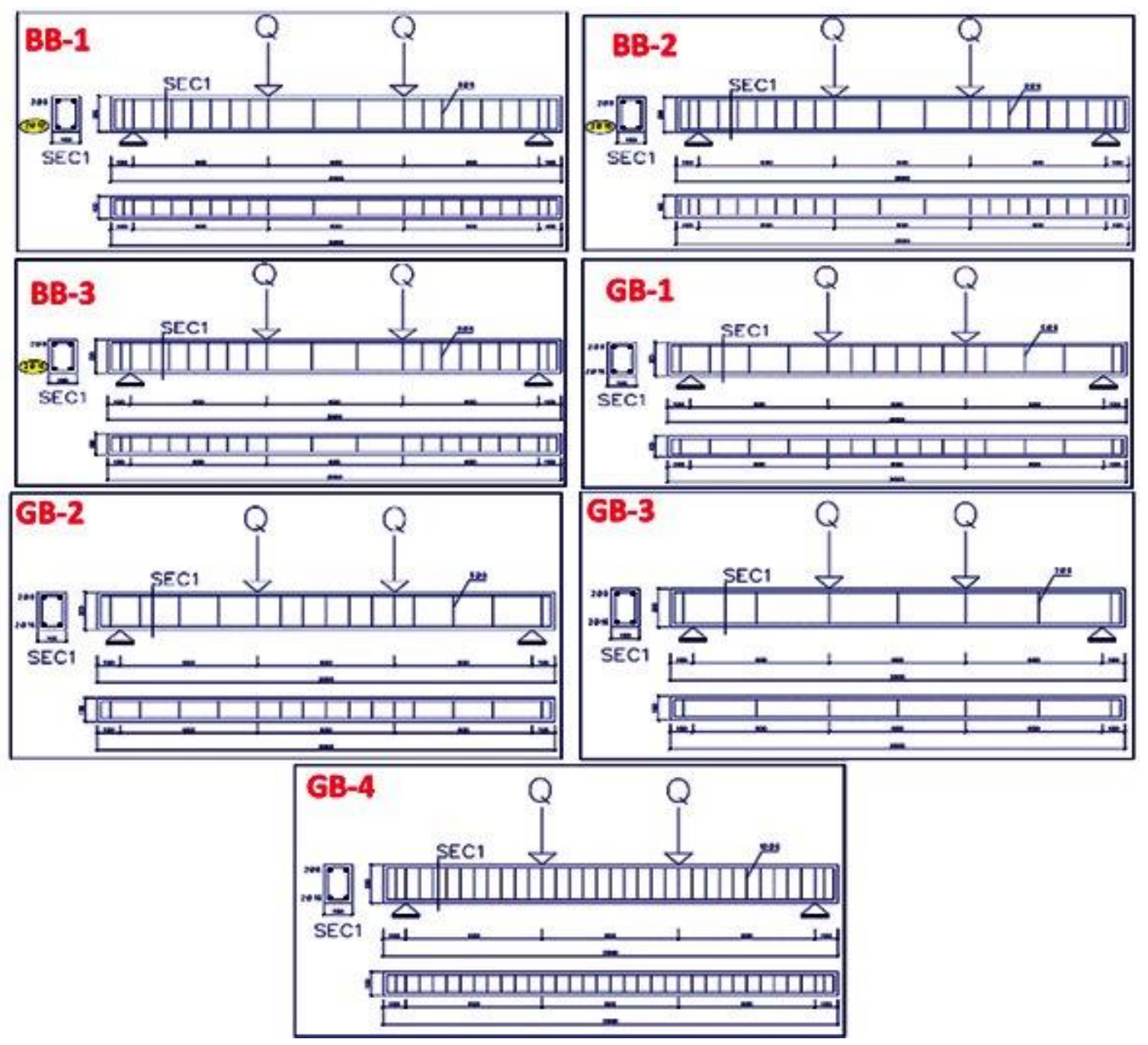

Fig 1. Details of reinforcement and concrete dimensions of all specimens

The UHSC beams have been investigated under two point- static loading machine with a capacity of $250 \mathrm{kN}$. A hydraulic jack was utilized to apply the static loading with an augmentation of $5 \mathrm{kN}$ to failure. At each stage, the applied load was remained constant for about $10 \mathrm{~min}$. At the same time, the readings were taken and recorded. The effective beam span is $1600 \mathrm{~mm}$. The interval between the two loads points is $300 \mathrm{~mm}$. A linear variable displacement transducer has been used to find beams maximum deflections. It was put at the mid-point and in the bottom of the beam as shown in Fig. 2. The applied load was augmented till the failure the beams. The crack patterns were examined at each loading stages. A computerized data acquisition system were used to record the outcomes. 


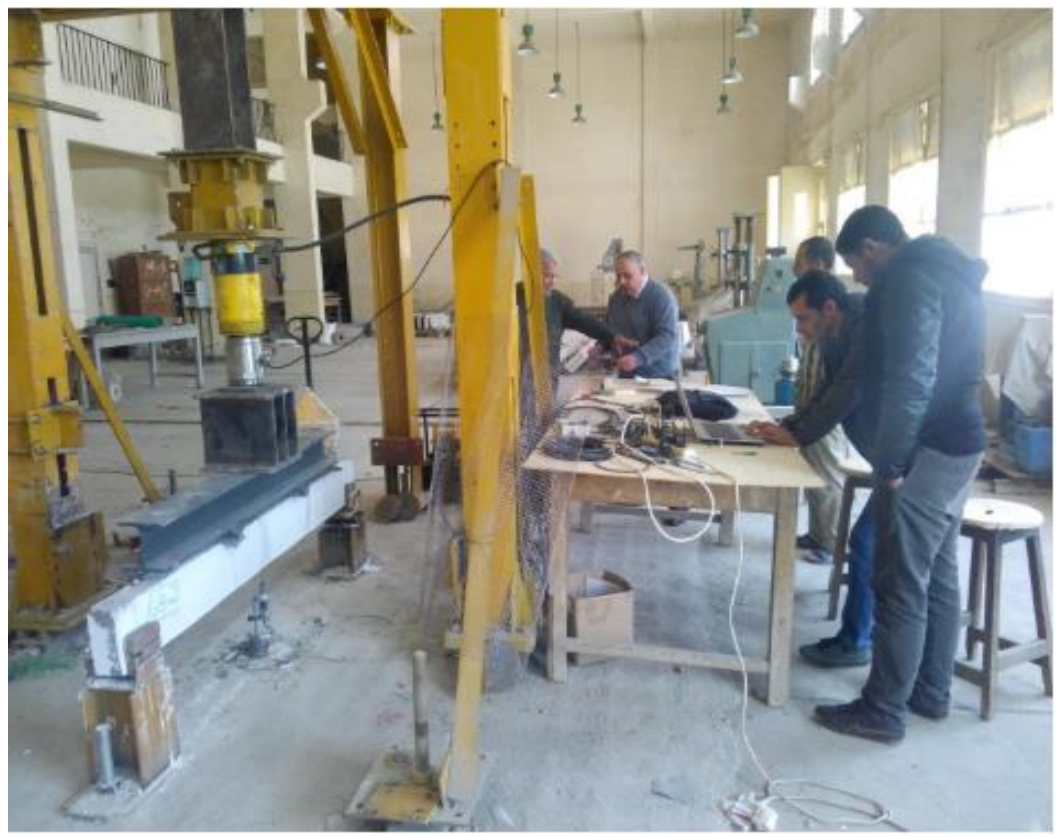

\section{RESULTS AND DISCUSSIONS}

Fig 2. Set up of test beams

\subsection{Properties of concrete}

\subsubsection{Fresh concrete}

The slump test was conducted to evaluate the workability of UHSC which prepared from Egyptian local materials. The obtained findings indicated that the slump test value of UHSC is $9 \mathrm{~cm}$.

\subsection{Mechanical properties}

\subsubsection{Compressive strength}

The compressive strength of UHSC mix as a function of curing time for cubes and cylinders samples is depicted in Fig. 3. It is noticeable that the compressive strength of UHSC depends greatly on the curing time. As the curing time increases, as the compressive strength rises due to the cement hydration and the depletion of calcium hydroxide by the pozzolanic reaction of silica fume, which results in an increment of the hydration products and decreasing pore sizes. Further, silica fumes have very small sizes that have the ability to fill the voids. On the other hand, Fig. 3. shows that the ratios of cylinders to cubes samples are $90 \%, 87 \%$ and $85 \%$ after curing time of 7,28 , and 56 days, respectively. According to Eurocode 2 [18], the strength of cylinder is approximately $80 \%$ of the strength of cubes. The difference in strength between cubes and cylinders can be explained as follows: the micro-cracks are started under high stress values when the samples are in axial compression. However, due to presence of the coarse aggregates, the micro-cracks are hindered or prevented. With increment of numbers of micro-cracks, a remarkable expansion in radial direction is established but they are inhibited at the two ends owing to the frictions. For cubes samples, the friction restriction is stronger, causing a higher strength, and hence, they give higher strength [9]. 


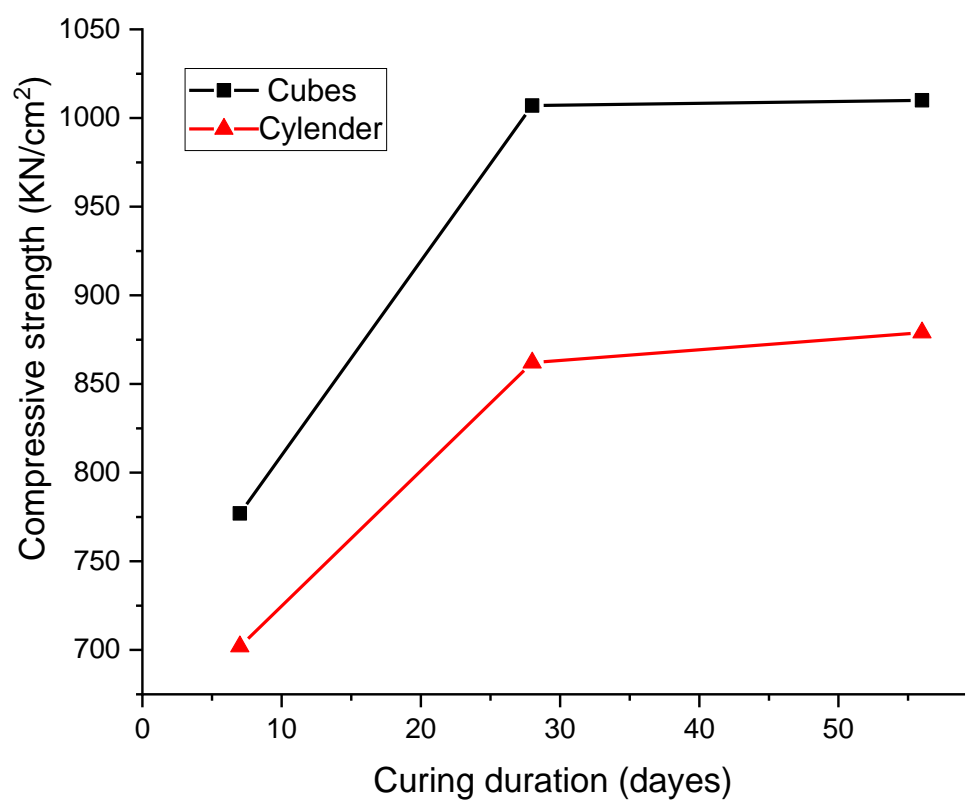

Fig. 3. Comparison between compressive strength of UHSC obtained by cubes and cylinders at different

\subsubsection{Splitting tensile strength}

curing time

The tensile strength is an essential factor that influences on the susceptibility of concrete to cracking. Therefore, the tensile strength of UHSC mix was evaluated at 7, 28 and 56 days. Fig. 4 displays the effect of curing time on the development of tensile strength for the investigated UHSC. Clearly, the behavior of the tensile strength of UHSC is comparable to the compressive strength, it increases with increasing curing time. However, the results show that the value of the tensile strength of concrete mix after 56 days similar to the value after 28 days. This means that curing time after 56 days did not produce an improvement on the tensile strength. The ratio between tensile strength to compressive strength is $38.5 \%$ and $36.6 \%$ at 7 and 28 days respectively.

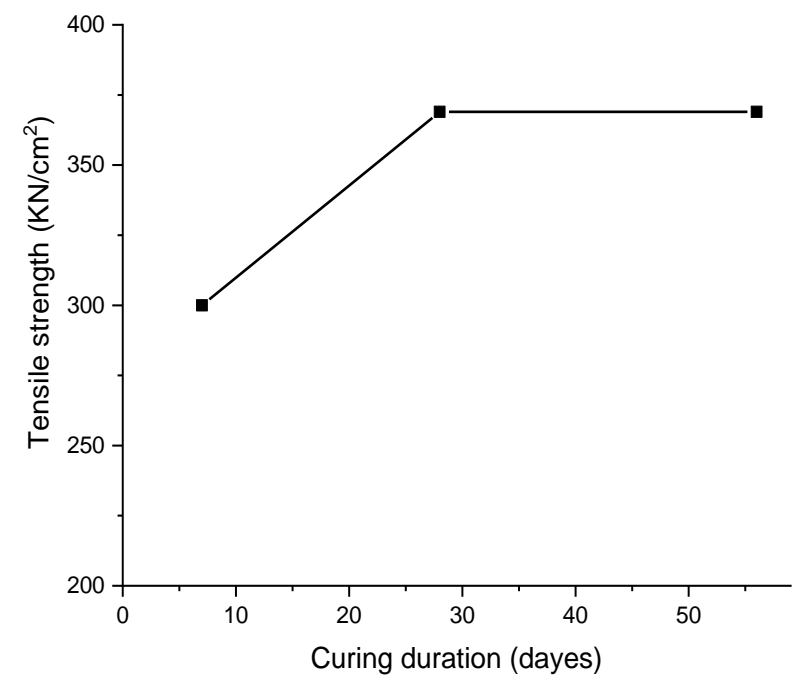

Fig. 4. Splitting tensile strength of UHSC at different curing time 


\subsection{Behavior of beams under static loading.}

\subsubsection{Load-deflection behavior}

The load-deflection of the investigated beams are given in Fig. 5. Obviously, the loaddeflection outcomes, illustrates two stages: the first stage presents an elastic behavior up to the existence of the first crack. Accordingly, the slope of the load-deflection curve in this stage is steeper. In the second stage, the flexural cracks starts to form and as the applied load increases, the cracks propagate, and their widths and heights increase. Furthermore, the outcomes show a non-linear deflection until the failure. This behavior reflects the plastic flow of the concrete beams. In contrast, Fig. 5 shows that the load-deflection response is not affected by growing the reinforcement at the pre-cracking stage. Nevertheless, the behavior is significantly altered at the cracking stage because of the influence of steel reinforcement in the cracked moment of inertia. Therefore, by increment of steel ratio, the maximum deflection is reduced.

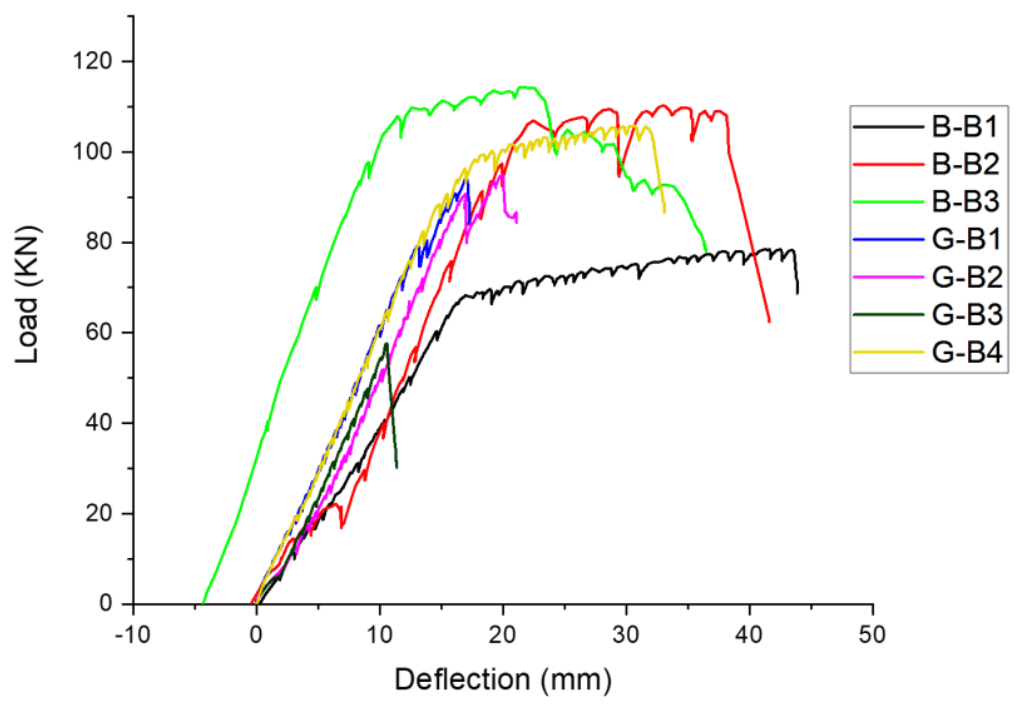

Fig. 5. The load-deflection curves of the investigated beams.

The ultimate failure loads and their corresponding deflections have been presented in Table 6 and Figs 6 and 7. Inspection of the outcomes illustrates that the deflection value of beam B-B1 is $43.13 \mathrm{~mm}$, obviously higher than that of all beams, while the corresponding ultimate load is $8 \mathrm{KN}$. Conversely, G-B1 gives the lowest deflection value $(11.38 \mathrm{~mm})$ with ultimate failure load of 5.7KN. Further, Figs 4 and 5 shows that G-B4 gives the highest value of ultimate failure load $(16 \mathrm{KN})$ with a corresponding deflection value of $33.62 \mathrm{~mm}$. 


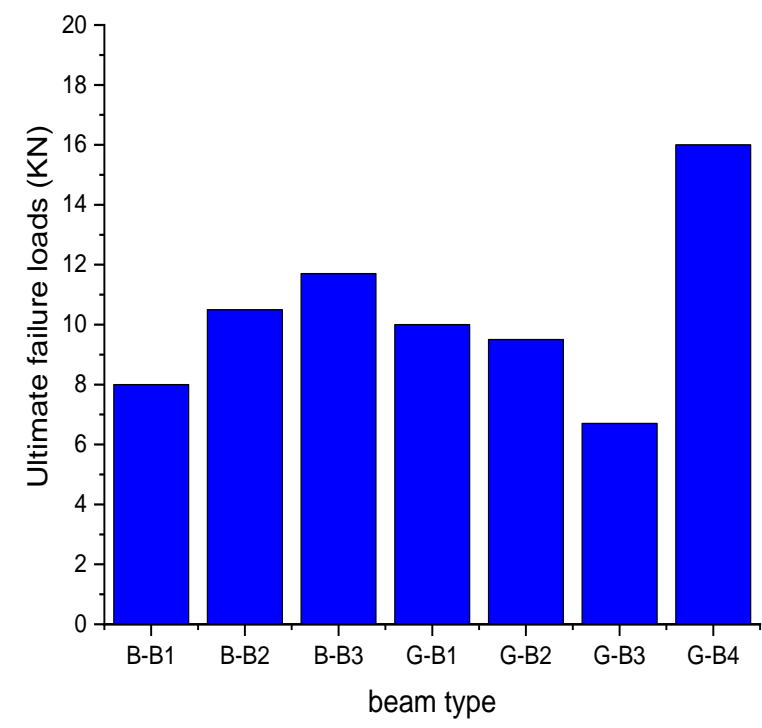

Fig. 6. The ultimate failure loads of the investigated beams.

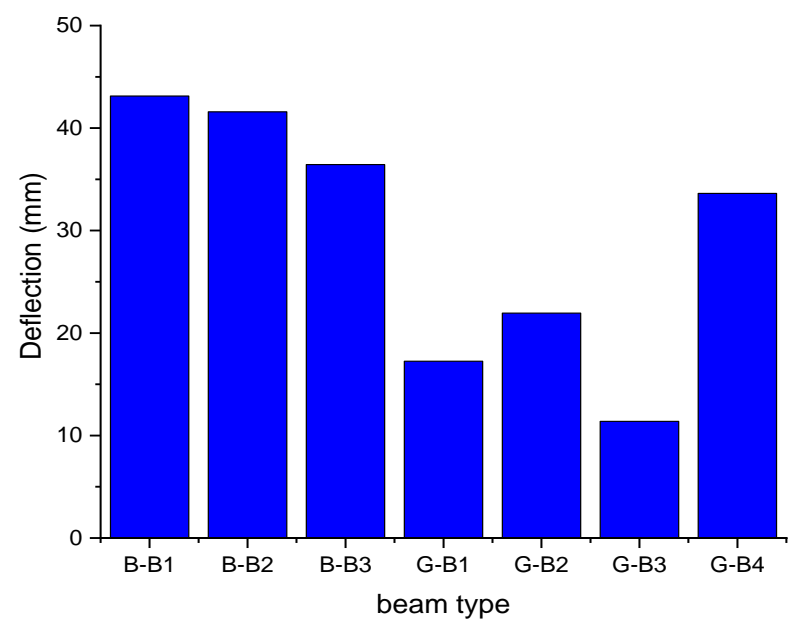

Fig. 7. The ultimate deflection of the investigated beams.

\subsubsection{Crack pattern}

The crack patterns as well as the failure mode of the investigated beams are shown in Figs. 8 and 9. Clearly, Fig 8 reveals that inside the middle third of the beams, the formed cracks are generally vertical owing to the pure moment applied on this zone, while the cracks are inclined outside this part of the beam. This behavior is attributed to the presence of shearing forces as well as the moment. Further, it was observed that the first crack in all specimens approximately occurred at midway of the critical shear zone. The flexural cracks have not observed in the zone of maximum bending moment as the applied load increased. On the other hand, Fig 9 depicts that the failure in the beams with low reinforcement is mainly flexural, while for the heavily reinforced beams the shearing failure is more noticeable. This leads to decreasing the height of flexural cracks in the middle part of the beam. 


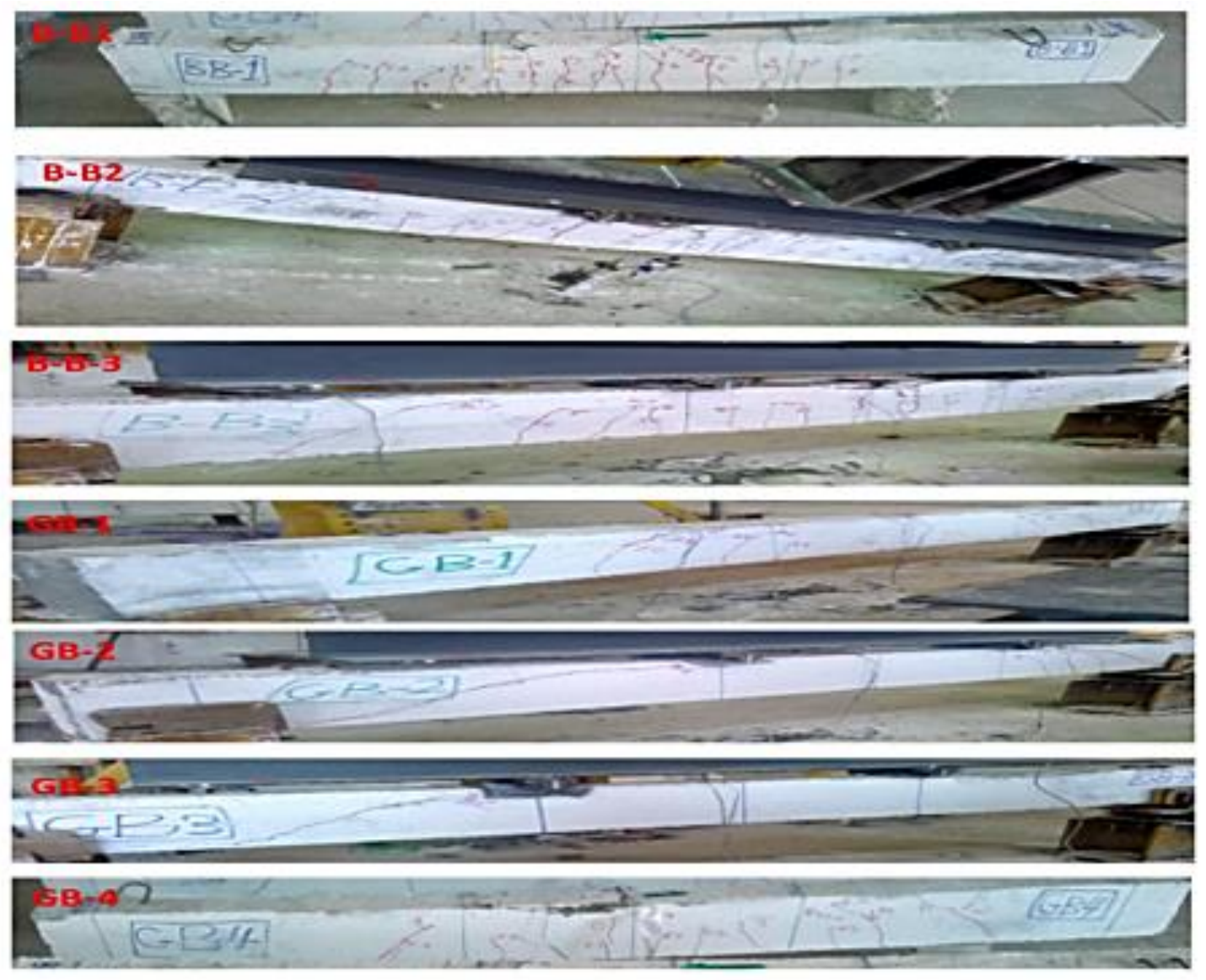

Fig. 8. Failure modes for the different tested beams.

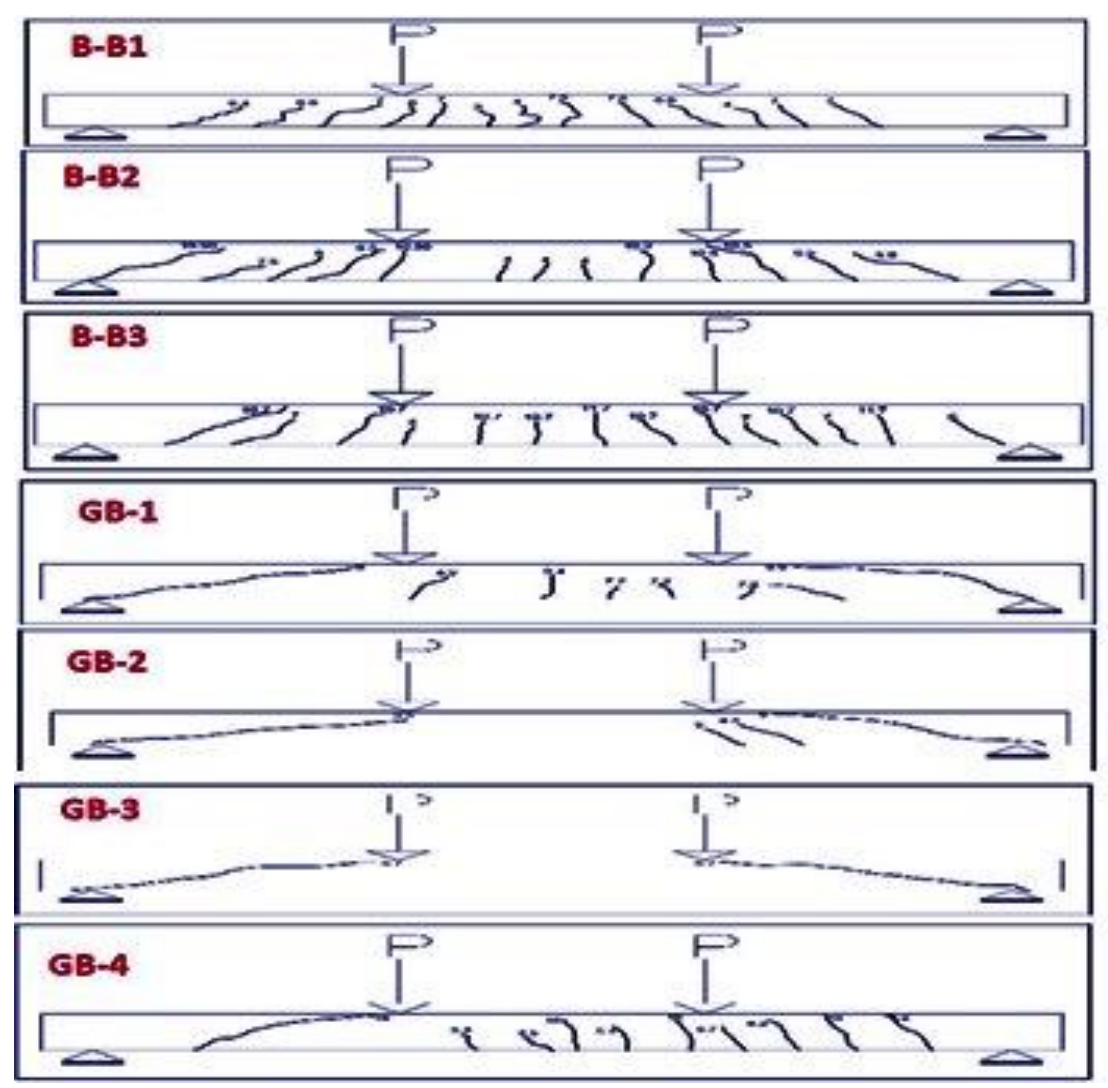

Fig. 9. Crack patterns for the different tested beams. 
For beams B-B1, B-B2 and B-B3, the initiation and propagation of the first crack have been detected at midway of the critical shear zone. By increasing the load, this crack developed further at both ends, no secondary cracks was observed up to the failure. The final failure mode of these beams as shown in Fig 9 is a diagonal tension crack at the critical shear zone. Furthermore, Figs. 8 depicts that for beams G-B1, G-B2, G-B3 and G-B4, the first visible crack was observed at the critical shear zone of the beams. The crack was extended by increasing the applied load. Although increasing the applied load, no secondary cracks were created in both shears adjacent. The crushing of concrete at the roller support was observed by failure. Fig 9 shows that the final mode of failure for G-B1, G-B2, G-B3 and G-B4 is a diagonal shear crack. A comparison between the first crack loads of the different beams is shown in Fig 10.

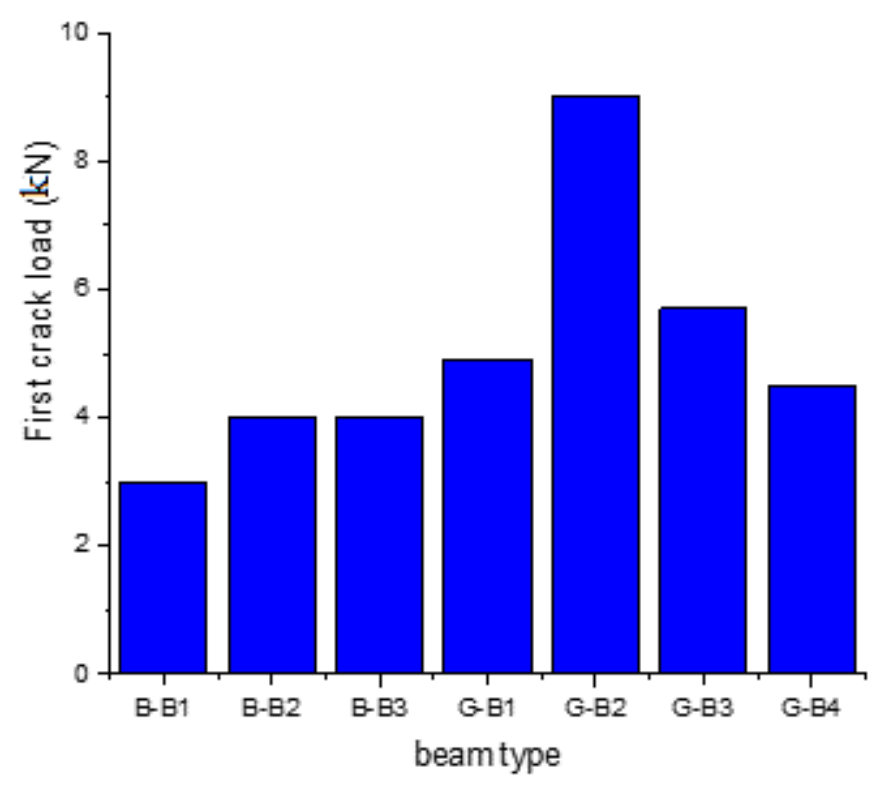

Fig. 10. Comparison between first crack loads for tested beams.

\subsubsection{Ductility}

The ratio between loads of the first crack to the failure loads can be defined as the ductility [19]. It characterizes the behavior of the beams owing to the presence of steel reinforcement. The higher this ratio, the more ductile is the beam [20]. Fig 11 displays a comparison between the ductility of the different UHSC beams. It can be obviously seen that the ductility ratio is varied from 28 to $94 \%$. Beams B-B1, B-B2 and B-B3 give ductility of 37, 38 and 34\%, respectively. The beam G-B4 gives the lowest ductility \% (about $28 \%$ ), while G-B3 provides the highest value (about 94\%). It depends on the number of stirrups and reinforcement ratio. 


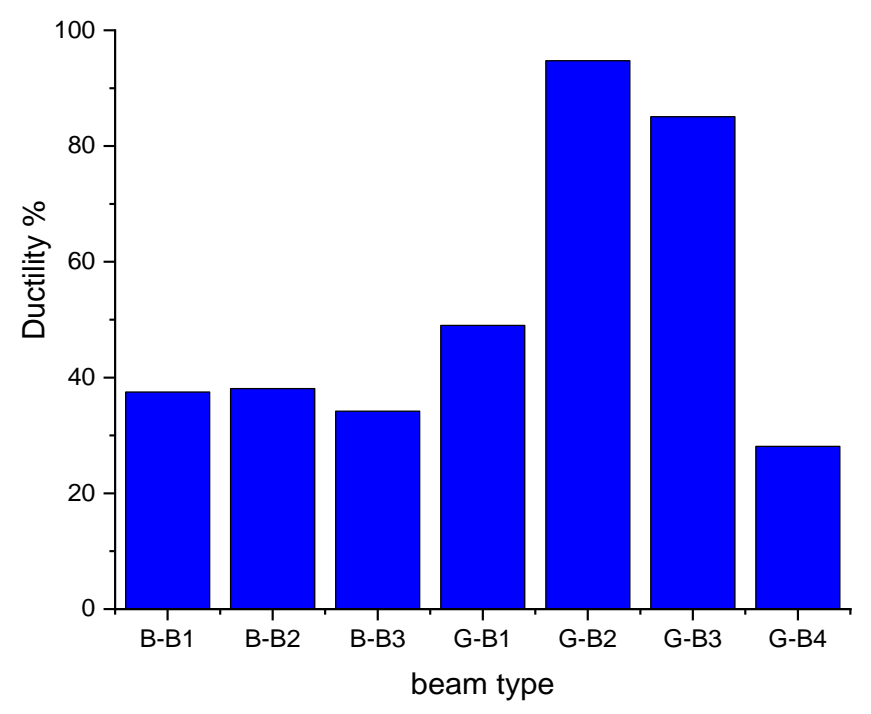

Fig .11 Comparison between the ductility for the tested beams.

\subsubsection{Concrete strain behavior}

Fig. 12 shows the strain values of UHSC. All beams exhibit a similar behavior. First, a precracking behavior, and then a post-cracking which increases the strains until the failure. This behavior is attributed to the reduction in post-cracking stiffness. However, the outcomes illustrated that beams B-B1, B-B2 and B-B3 have more strain values comparing to G-B1, GB2, G-B3, and G-B4 which exhibit low strain values. The behavior suggests that beams G-B1, G-B2, G-B3, and G-B4 are more brittle.

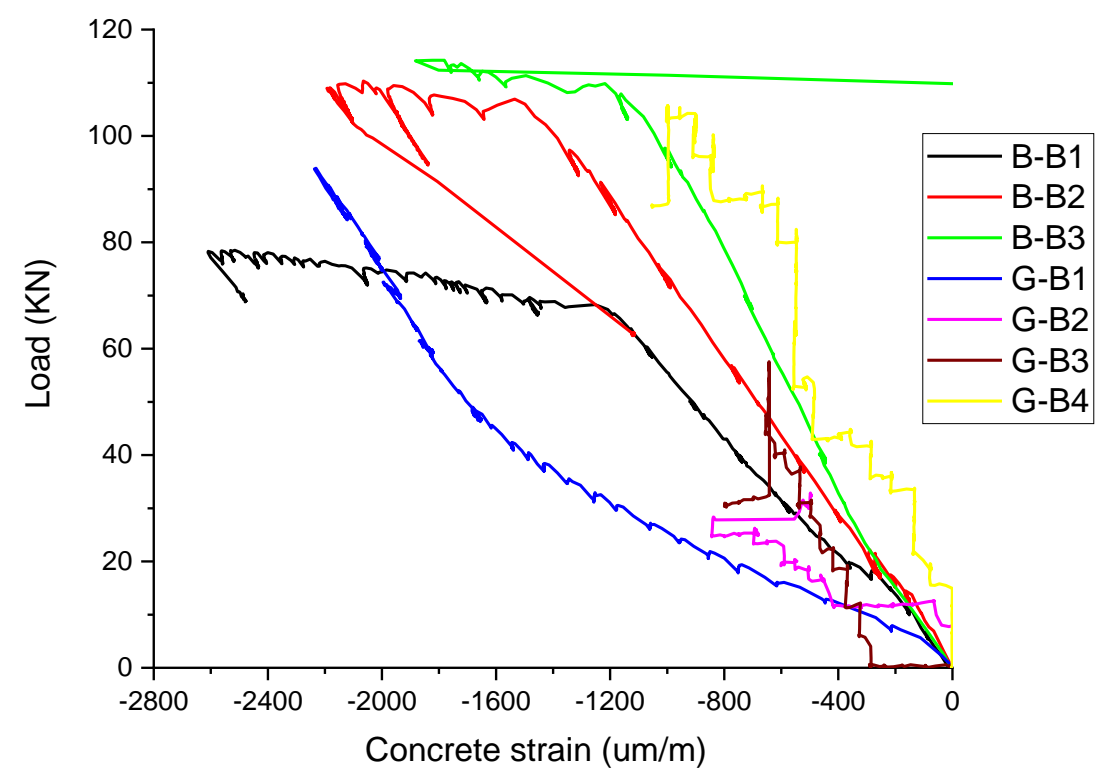

Fig 12. Strain values of UHSC for the tested beams.

\section{CONCLUSIONS}

In the present study, UHSC was prepared successfully from Egyptian materials. Depending on the outcomes which were obtained from this study, the following conclusions can be made: 
1) The compressive strength ratio between cylinders and cubes samples are $90 \%, 87 \%$ and $85 \%$ at 7,28 , and 56 days respectively, while the ratio between tensile strength to compressive strength is $38.5 \%$ and $36.6 \%$ at 7 and 28 days respectively.

2) The failure behavior was more brittle for beams G-B3 and G-B4, and it was a shear failure.

3) Increase of the reinforcement ratios, gives different crack behaviors as well as the reduction in reinforcement strain.

4) The reinforcement ratio possesses a slight effect on the deflection and the strain of the tested beams at initial stages before cracking. However, beams which have a higher reinforcement give the lowest deflection and strain after cracking, owing to increasing the stiffness.

5) Increment of the bar diameter from $\emptyset=12 \mathrm{~mm}$ to $\emptyset=16 \mathrm{~mm}$, both cracking and failure loads have been augmented significantly.

6) The ductility ratio of the beam increased with increment of the reinforcement ratio.

7) The ratio between cube and cylinders compressive strength of (UHSC) at different ages was: $\mathrm{fc} 7 / \mathrm{fc} 28=0.77, \mathrm{fc} 56 / \mathrm{fc} 28=1.01 \& \mathrm{Fc} 7 / \mathrm{fc} 28=0.81 \mathrm{fc} 56 / \mathrm{fc} 28=1.03$ respectively.

8) The ratio between tensile strength to compressive strength ( $\mathrm{ft} / \mathrm{fc}$ ) at 28 days $=0.34$.

9) The failure behavior was more brittle for GB2 \& GB4, and the failure was shear failure.

\section{REFERENCES}

1. He Zhen-jun, Ma Yan-ni, Wang Zhen-wei, Zhang Xiao-jie, Zhang Xue-sheng, Ding Meng-jia, Fu Chuan, Structures 30 (2021) 1127-1138.

2. M.X. Xiong, J.Y.R. Liew, Mechanical bahviour of ultra-high strength concrete at elevated temperatures and fire resistance of ultra-high strength concrete filled steel tubes, Mater. Des. 104 (2016) 414-427.

3. M.X. Xiong, D.X. Xiong, J.Y.R. Liew, Flexural performance of concrete filled tubes with high tensile steel and ultra-high strength concrete, J. Constr. Steel Res. 132 (2017) 191-202

4. N.N. Meleka, A.A. Bashandy, M.A. Arab, Ultra high strength concrete using economical materials, International Journal of Current Engineering and Technology 3 (2) (2013) 393-402.

5. S. Allena, C.M. Newtson, Ultra-high strength concrete mixtures using local materials, in: Proceedings of International Concrete Sustainability Conference, Tempe, AZ, USA, 2010.

6. Yong Du, Hong-Hui Qi, Shan-Shan Huang, J.Y. Richard Liew, Experimental study on the spalling behaviour of ultra-high strength concrete in fire, Construction and Building Materials 258 (2020) 120334

7. S.M. Mousavi, M.M. Ranjbar, R. Madandoust, Combined effects of steel fibers and water to cementitious materials ratio on the fracture behavior and brittleness of high strength concrete, Eng. Fract. Mech. 216 (2019) 106517.

8. R. M. El Shazly, M. M. Sadawy, Effect of slag as a fine aggregate on mechanical,corrosion and nuclear attenuation properties of concrete. IJSER, 5(7), (2017) 2347-3878.

9. Ming-Xiang Xiong, J.Y. Richard Liew, Yan-Bo Wang, De-Xin Xiong, Bing-Lin Lai, Effects of coarse aggregates on physical and mechanical properties of C170/185 ultra- 
high strength concrete and compressive behaviour of CFST columns, Construction and Building Materials 240 (2020) 117967.

10. K. Rozalija, D. Darwin, Effects of Aggregate Type, Size, and Content on Concrete Strength and Fracture Energy, Lawrence, Kansas, 1997

11. Le Huang, Jin-Cheng Liu, Rongjin Cai, Hailong Ye, Mechanical degradation of ultrahigh strength alkali-activated concrete subjected to repeated loading and elevated temperatures, Cement and Concrete Composites 121 (2021) 104083

12. Jianyang Xue, Xiangbi Zhao, Xiaojun Ke, Xin Zhang, Fengliang Zhang, Peng Zhang, Experimental and numerical investigation of high-strength concrete encased steel columns with rectangular-spiral stirrups, Journal of Building Engineering 32 (2020) 101518.

13. Su Tae Kang, Bang Yeon Lee, Jin-Keun Kim, Yun Yong Kim, The effect of fibre distribution characteristics on the flexural strength of steel fibre-reinforced ultra high strength concrete, Construction and Building Materials 25 (2011) 2450-2457.

14. A. A. Semendary, W. K. Hamid, E. P. Steinberg, I. Khoury, Shear friction performance between high strength concrete (HSC) and ultra high performance concrete (UHPC) for bridge connection applications, Engineering Structures 205 (2020) 110122.

15. Dao Hoang Hiep Phan, Vipulkumar Ishvarbhai Patel, Qing Quan Liang, Haider Al Abadi,Huu-Tai Thai Simulation of uniaxially compressed square ultra-high-strength concrete-filled steel tubular slender beam-columns, Engineering Structures 232 (2021) 111795

16. H. Kimura, Y. Ishikawa, A. Kamabayashi, H. Takatsu. Seismic behavior of $200 \mathrm{MPa}$ ultrahigh-strength steel-fiber reinforced concrete columns under varying axial load. J Adv Concr Technol 2007; 5(2):193-200.

17. M.M. Kamal, M.A. Safan, Z.A. Etman, R.A. Salama, Behavior and strength of beams cast with ultra high strength concrete containing different types of fibers, HBRC Journal (2014) 10, 55-63

18. EN 1992-1-1, Eurocode 2: Design of concrete structures - Part 1-1: General rules and rules for buildings, 2004.

19. Abeer M. Erfan, Hossam E. Hassan, Khalil M. Hatab, Taha A. El-Sayed, The flexural behavior of nano concrete and high strength concrete using GFRP, Construction and Building Materials 247 (2020) 118664.

20. T. Tahenni, M. Chemrouk, T. Lecompte, Effect of steel fibers on the shear behavior of high strength concrete beams, Construction and Building Materials 105 (2016) 14-28. 